\title{
Association of serum phosphorus, calcium and parathyroid hormone with echocardiographic findings in regular hemodialysis patients
}

\author{
Alireza Nematollahi ${ }^{1}$, Mohammad-Reza Tamadon ${ }^{2}$, Parisa Irannejad ${ }^{1}$, Milad Fouladgar ${ }^{1}$, Mohammad \\ Bahadoram $^{3}$, Saeed Mardani ${ }^{*}$
}

\begin{abstract}
Introduction: Dialysis patients tend to have a greater prevalence of cardiovascular diseases.

Objectives: The aim of this study was to determine the prevalence of heart valves calcification, left ventricular hypertrophy, and left ventricular systolic and diastolic dysfunction. It also aimed to determining the relationship of the above mentioned parameters with serum calcium, phosphorus, parathormone and duration of dialysis.

Patients and Methods: This cross-sectional study was conducted on 100 hemodialysis patients who were referred to Hajar hospital in Shahrekord, Iran. Using echocardiography, patients were examined for the calcification of the heart valves, left ventricular hypertrophy, and left ventricular systolic and diastolic dysfunction. Serum calcium, phosphorus, and parathormone and duration of dialysis was also determined.

Results: The mean age of the patients was $58.10 \pm 15.51$ years. Around 24 patients suffered from calcification of the heart valves. Additionally, 85 patients suffered from left ventricular hypertrophy. The prevalence of left ventricular systolic and diastolic dysfunction was $26 \%$ and $86 \%$, respectively. Common valvular abnormalities were mitral valve regurgitation (97\%), followed by tricuspid regurgitation, aortic and pulmonary regurgitation, respectively. There was a significant relationship between serum phosphorus and calcification of cardiac valves, left ventricular hypertrophy, and left ventricular systolic dysfunction $(P<0.05)$. Duration of dialysis and calcium and serum parathyroid hormone levels had no significant relationship with left ventricular hypertrophy and dysfunction and calcification of cardiac valves $(P>0.05)$.

Conclusion: Cardiovascular diseases are common among hemodialysis patients. Hyperphosphatemia is a risk factor for the prevalence of left ventricular hypertrophy, left ventricular systolic dysfunction and calcification of the heart valves.

Keywords: Hyperphosphatemia, Hemodialysis patients, Valvular calcification, Left ventricular hypertrophy

Please cite this paper as: Nematollahi A, Tamadon MR, Irannejad P, Fouladgar M, Bahadoram M, Mardani S. Association of serum phosphorus, calcium and parathyroid hormone with echocardiographic findings in regular hemodialysis patients. J Parathyr Dis. 2018;6(2):44-49. DOI: 10.15171/jpd.2018.17.

Copyright (c) 2018 The Author(s); Published by Nickan Research Institute. This is an open-access article distributed under the terms of the Creative Commons Attribution License, which permits unrestricted use, distribution, and reproduction in any medium, provided the original work is properly cited.
\end{abstract}

\section{Introduction}

Chronic renal failure (CRF) is an irreversible decline of renal function which finally leads to end-stage renal disease (ESRD). This condition is associated with renal replacement therapy including dialysis or transplantation (1). The annual rate of mortality from cardiovascular diseases in hemodialysis patients is around 9\%, which is 30 times higher than that in general population (2). Ischemic heart diseases, atherosclerosis, myocardial dysfunction followed by heart failure, left ventricular hypertrophy and calcification of the heart valves are common diseases in hemodialysis patients $(1,2)$. The high rates of cardiac complications in hemodialysis patients might be attributed to the higher prevalence of major risk factors among these patients, including high blood pressure, anemia, increased blood volume, arteriovenous fistula, uremia, calcium and phosphorous imbalance and dyslipidemia. Other factors that are specifically related to hemodialysis patients and increase the rates of cardiovascular disease, included stress on myocardium caused by increased intravascular volume load, increase or decrease of trace elements that act as enzymatic factors and finally factors that inhibit myocardial ATPase $(3,4)$. The progress of chronic kidney disease leads to the development of hyperphosphatemia, which increases the mortality. Hyperphosphatemia reduces serum levels of calcium via making a connection between calcium and phosphate and chronically inhibiting renal alpha-hydroxylase activity and reducing the synthesis of 1,25-dihydroxyvitamin $\mathrm{D}$. The reduction of 1,25-dihydroxyvitamin $\mathrm{D}$ and calcium in the serum will

Received: 10 March 2017, Accepted: 20 September 2017, ePublished: 9 October 2017

${ }^{1}$ Department of Internal Medicine, Shahrekord University of Medical Sciences, Shahrekord, Iran. ${ }^{2}$ Department of Internal Medicine, Semnan University of Medical Sciences, Semnan, Iran. ${ }^{3}$ Medical Student Research Committee, Faculty of Medicine, Ahvaz Jundishapur University of Medical Sciences, Ahvaz, Iran.

*Corresponding author: Saeed Mardani, Email: Dr_s_mardani@yahoo.com 
Implication for health policy/practice/research/ medical education

Hyperphosphatemia is a risk factor for the prevalence of left ventricular hypertrophy, left ventricular systolic dysfunction and calcification of the heart valves.

stimulate the parathyroid gland to secrete the parathyroid hormone (5). Acute or chronic hyperphosphatemia may cause metastatic calcification in people with normal or high levels of calcium (6).

Secondary hyperparathyroidism, which is characterized by elevated serum levels of parathyroid hormone, parathyroid gland hyperplasia, and imbalance of calcium and phosphorus metabolism, is common in hemodialysis patients. Parathyroid hormone is a uremic toxin causing renal osteodystrophy, calcification of the cardiovascular system and heart valves, changes in cardiovascular function and structure, immunodeficiency and anemia (7). Increased plasma levels of parathormone have been reported to increase the risk of hypertrophy and left ventricular failure in hemodialysis patients (1).

\section{Objectives}

It has been shown in various studies that calcium, phosphorus, and serum parathormone levels play a pivotal role in the progression of heart disease in hemodialysis patients. Therefore, the aim of this study was to investigate the prevalence of some cardiac diseases including calcification of the cardiac valves, left ventricular systolic and diastolic dysfunction, and left ventricular hypertrophy in hemodialysis patients. It was also aimed to determine their relationship with calcium, phosphorus, and serum parathormone levels and duration of hemodialysis.

\section{Patients and Methods}

Study population

This cross-sectional study was performed on patients with ESRD who were on regular hemodialysis 3 times a week for at least 6 months in Hajar hospital in Shahrekord, Iran. Exclusion criteria were: ages under 18 and over 80, past history of systolic heart failure and and coronary artery disease. First, general information such as name, age, weight, BMI, gender, duration of hemodialysis, frequency of hemodialysis per week, and history of cardiac risk factors were recorded using a questioner. Patients' blood samples were sent to the laboratory to determine the levels of calcium, phosphorus, intact parathormone (iPTH), and the ratio of blood urea nitrogen (BUN) to creatinine. The ratio of BUN to creatinine was measured pre- and post-dialysis. Echocardiography was conducted using an echocardiographic device (GE Vivid S6 ultrasound system). Echocardiographic findings including left ventricular systolic and diastolic function, left ventricular wall thickness and dimensions, and valvular heart disease and calcification were recorded. It should be noted that patients were divided into three groups regarding of the duration of dialysis ( 6 months to 3 years, 3 to 5 years, and more than 5 years).

\section{Ethical issues}

This research was performed following the Declaration of Helsinki principles. The Ethics Committee of Shahrekord University of Medical Sciences approved the study (proposal \# 1893). This article is extracted from general practitioner thesis of Parisa Irannejad. Informed consent was obtained and all information of patients was coded and kept confidential.

\section{Statistical analysis}

Laboratory and echocardiographic data including left ventricular systolic and diastolic function, left ventricular wall thickness and dimensions, and valvular heart disease and calcification were gathered. SPSS version 19 was used for data analysis. One-way analysis of variance (ANOVA) with post-hoc Tukey's test were used when appropriate. All results are expressed as mean and standard deviation (SD) and $P$ value below 0.05 was considered significant.

\section{Results}

Of 100 studied patients, $64 \%$ were male. The mean age of the patients was $58.10 \pm 15.51$ years. Further details are presented in Table 1.

In this study we found, $71 \%$ of patients had mild left ventricular hypertrophy, $13 \%$ had moderate left ventricular hypertrophy, and $1 \%$ had severe left ventricular hypertrophy, while $15 \%$ of patients did not have left ventricular hypertrophy. We also found, no significant relationship of serum calcium and parathyroid hormone, with left ventricular hypertrophy; however, a significant relationship of serum phosphorus and left ventricular hypertrophy was detected (Table 2).

There was a significant difference in phosphorus levels

Table 1. Laboratory data and Echocardiographic findings of hemodialysis patients

\begin{tabular}{ll}
\hline Variable & Mean \pm SD \\
\hline Pre-dialysis blood urea nitrogen $(\mathrm{mg} / \mathrm{dL})$ & $68.10 \pm 18.64$ \\
Post-dialysis blood urea nitrogen $(\mathrm{mg} / \mathrm{dL})$ & $21.94 \pm 7.21$ \\
Creatinine $(\mathrm{mg} / \mathrm{dL})$ & $8.61 \pm 2.98$ \\
Calcium $(\mathrm{mg} / \mathrm{dL})$ & $8.99 \pm 0.38$ \\
Phosphorus $(\mathrm{mg} / \mathrm{dL})$ & $5.02 \pm 1.24$ \\
iPTH $(\rho g / \mathrm{mL})$ & $445.44 \pm 372.88$ \\
Late left ventricular filling velocity $(\mathrm{A})(\mathrm{m} / \mathrm{s})$ & $0.86 \pm 0.29$ \\
Early left ventricular filling velocity $(\mathrm{E})(\mathrm{m} / \mathrm{s})$ & $1.50 \pm 5.31$ \\
E/A ratio & $0.94 \pm 0.49$ \\
Deceleration time $(\mathrm{ms})$ & $266.91 \pm 97.98$ \\
Deceleration slope $(\mathrm{cm} / \mathrm{s})$ & $3.685 \pm 21.10$ \\
\hline
\end{tabular}


Table 2. Serum calcium, phosphorus, and parathormone levels in patients with and without left ventricular hypertrophy

\begin{tabular}{|c|c|c|c|}
\hline & Left ventricular hypertrophy & Mean \pm SD & $P$ value \\
\hline & Normal & $9.08 \pm 0.38$ & \\
\hline \multirow[t]{3}{*}{ Calcium (mg/dL) } & Mild left ventricular hypertrophy & $8.95 \pm 0.38$ & 0.21 \\
\hline & Moderate and severe left ventricular hypertrophy & $9.10 \pm 0.32$ & \\
\hline & Normal & $498.60 \pm 378.96$ & \\
\hline \multirow[t]{3}{*}{ iPTH $(\rho g / m L)$} & Mild left ventricular hypertrophy & $441.27 \pm 376.47$ & 0.834 \\
\hline & Moderate and severe left ventricular hypertrophy & $433.00 \pm 336.87$ & \\
\hline & Normal & $4.27 \pm 0.67$ & \\
\hline \multirow[t]{2}{*}{ Phosphorus (mg/dL) } & Mild left ventricular hypertrophy & $5.13 \pm 1.27$ & 0.028 \\
\hline & Moderate and severe left ventricular hypertrophy & $5.30 \pm 1.60$ & \\
\hline
\end{tabular}

between normal and mild left ventricular hypertrophy groups $(P=0.035)$, however the difference between normal with moderate and severe left ventricular hypertrophy groups was slightly significant $(P=0.067)$. Table 3 presents the data of left ventricular systolic and diastolic function in hemodialysis patients.

Accordingly, serum calcium and parathyroid hormone levels had no significant relationship with left ventricular

Table 3. Comparison of left ventricular systolic and diastolic function in patients undergoing hemodialysis

\begin{tabular}{lc}
\hline & No. (\%) \\
\hline Left ventricular systolic function & \\
Normal & $58(58)$ \\
Preserved function & $16(16)$ \\
Mild dysfunction & $16(16)$ \\
Moderate dysfunction & $9(9)$ \\
Severe dysfunction & $1(1)$ \\
Left ventricular diastolic function & \\
Normal & $13(13)$ \\
Grade I dysfunction & $81(81)$ \\
Grade II dysfunction & $4(4)$ \\
Grade III dysfunction & $2(2)$ \\
\hline
\end{tabular}

Table 4. Serum calcium, phosphorus, and parathormone levels in patients with and without left ventricular systolic dysfunction

\begin{tabular}{|c|c|c|c|}
\hline & $\begin{array}{l}\text { Left ventricular systolic } \\
\text { function }\end{array}$ & Mean \pm SD & $P$ value \\
\hline \multirow{4}{*}{$\begin{array}{l}\text { Calcium } \\
\text { (mg/dL) }\end{array}$} & Normal & $8.96 \pm 0.3552$ & \multirow{4}{*}{0.35} \\
\hline & Preserved function & $9.02 \pm 0.3022$ & \\
\hline & Mild dysfunction & $9.13 \pm 0.4801$ & \\
\hline & $\begin{array}{l}\text { Moderate to severe } \\
\text { dysfunction }\end{array}$ & $8.90 \pm 0.4522$ & \\
\hline \multirow{4}{*}{$\begin{array}{l}\text { iPTH } \\
(\rho \mathrm{g} / \mathrm{mL})\end{array}$} & Normal & $463.07 \pm 373.749$ & \multirow{4}{*}{0.978} \\
\hline & Preserved function & $472.50 \pm 367.505$ & \\
\hline & Mild dysfunction & $359.45 \pm 413.735$ & \\
\hline & $\begin{array}{l}\text { Moderate to severe } \\
\text { dysfunction }\end{array}$ & $434.00 \pm 362.317$ & \\
\hline \multirow{4}{*}{$\begin{array}{l}\text { Phosphorus } \\
\text { (mg/dL) }\end{array}$} & Normal & $4.84 \pm 1.0005$ & \multirow{4}{*}{0.01} \\
\hline & Preserved function & $4.88 \pm 1.1295$ & \\
\hline & Mild dysfunction & $5.63 \pm 1.8304$ & \\
\hline & $\begin{array}{l}\text { Moderate to severe } \\
\text { dysfunction }\end{array}$ & $4.79 \pm 1.2453$ & \\
\hline
\end{tabular}

systolic function. However, serum phosphorus levels had a significant relationship with left ventricular systolic function (Table 4). There was a significant difference in phosphate levels between normal and mild left ventricular systolic dysfunction groups $(P=0.014)$ while no significant difference of mild systolic dysfunction and preserved left ventricular systolic function groups was observed $(\mathrm{P}=$ 0.097) (Table 4). Moreover, serum calcium, phosphorus, and parathyroid hormone levels had no significant relationship with left ventricular diastolic dysfunction $(P>0.05$; Table 5$)$.

Table 6 presents the data on the prevalence of aortic and mitral valves and their annulus calcification in hemodialysis patients. Common valvular abnormalities were mitral valve regurgitation (97\%), followed by tricuspid, aortic and pulmonary regurgitation respectively.

Table 5. Serum calcium, phosphorus, and parathormone levels in patients with and without left ventricular diastolic dysfunction

\begin{tabular}{llcc}
\hline & $\begin{array}{l}\text { Left ventricular diastolic } \\
\text { dysfunction }\end{array}$ & Mean \pm SD & P value \\
\hline & Normal & $8.98 \pm 0.42$ & \\
Calcium & Grade I & $9.00 \pm 0.38$ & 0.88 \\
(mg/dL) & Grade II & $8.85 \pm 0.26$ & \\
& Grade III & $8.95 \pm 0.07$ & \\
& Normal & $413.23 \pm 403.99$ & \\
iPTH & Grade I & $461.26 \pm 366.07$ & 0.82 \\
( $\rho$ g/mL) & Grade II & $375.50 \pm 459.81$ & \\
& Grade III & $654.00 \pm 567.100$ & \\
& Normal & $5.25 \pm 1.21$ & \\
Phosphorus & Grade I & $4.97 \pm 1.26$ & 0.71 \\
(mg/dL) & Grade II & $4.92 \pm 0.89$ & \\
& Grade III & $5.80 \pm 1.69$ & \\
\hline
\end{tabular}

Table 6. Comparison of the heart valves calcification in hemodialysis patients

\begin{tabular}{lc}
\hline Calcification & Proportion (\%) \\
\hline Calcification of the aortic valve & $20(20)$ \\
Calcification of mitral valve & $1(1)$ \\
Calcification of mitral annulus & $4(4)$ \\
Mitral and aortic annuluses calcification & $6(6)$ \\
Without calcification & $69(69)$ \\
\hline
\end{tabular}


Table 7. Serum calcium, phosphorus, and parathormone levels in patients with and without heart valve calcification

\begin{tabular}{|c|c|c|c|}
\hline & Calcification & Mean \pm SD & $P$ value \\
\hline \multirow{5}{*}{$\begin{array}{l}\text { Calcium } \\
\text { (mg/dL) }\end{array}$} & Aortic valve & $9.07 \pm 0.41$ & \multirow{5}{*}{0.084} \\
\hline & Mitral annulus & $9.05 \pm 0.31$ & \\
\hline & Mitral valve & $8.50 \pm 0.17$ & \\
\hline & Without calcification & $9.01 \pm 0.36$ & \\
\hline & $\begin{array}{l}\text { Mitral and aortic annuluses } \\
\text { calcification }\end{array}$ & $8.60 \pm 0.33$ & \\
\hline \multirow{5}{*}{$\begin{array}{l}\text { ¡PTH } \\
(\rho g / m L)\end{array}$} & Aortic valve & $413.30 \pm 325.25$ & \multirow{5}{*}{0.501} \\
\hline & Mitral annulus & $608.75 \pm 371.50$ & \\
\hline & Mitral valve & $173.00 \pm 0.00$ & \\
\hline & Without calcification & $452.97 \pm 391.77$ & \\
\hline & $\begin{array}{l}\text { Mitral and aortic annuluses } \\
\text { calcification }\end{array}$ & $556.17 \pm 351.300$ & \\
\hline \multirow{5}{*}{$\begin{array}{l}\text { Phosphorus } \\
\text { (mg/dL) }\end{array}$} & Aortic valve & $5.00 \pm 1.35$ & \multirow{5}{*}{0.784} \\
\hline & Mitral annulus & $5.65 \pm 1.06$ & \\
\hline & Mitral valve & $6.00 \pm 0.00$ & \\
\hline & Without calcification & $4.99 \pm 1.261$ & \\
\hline & $\begin{array}{l}\text { Mitral and aortic annuluses } \\
\text { calcification }\end{array}$ & $4.86 \pm 0.88$ & \\
\hline
\end{tabular}

Table 8. Left ventricular wall thickness $(\mathrm{mm})$ in hemodialysis patients

\begin{tabular}{lccccc}
\hline & $<1$ year & $\mathbf{1 - 3}$ years & 3-5 years & $>5$ years & $\boldsymbol{P}$ \\
\hline $\operatorname{IVSd}(\mathrm{cm})^{\mathrm{a}}$ & $1.1 \pm 0.28$ & $1.15 \pm 0.181$ & $1.16 \pm 0.17$ & $1.1 \pm 0.011$ & 0.49 \\
$\mathrm{LVPWd}(\mathrm{cm})^{\mathrm{a}}$ & $1 \pm 0.11$ & $1.07 \pm 0.15$ & $1.13 \pm 0.19$ & $1.07 \pm 0.14$ & 0.65 \\
\hline
\end{tabular}

${ }^{a}$ Values are presented as mean $\pm \mathrm{SD}$.

We found, no significant relationship of serum calcium, phosphorus and parathyroid hormone with calcification of the valves (Table 7).

Table 8 shows the data of the end diastolic interventricular septum (IVSd) and left ventricular posterior wall thickness (LVPWd). We detected that diastolic interventricular septum (IVSd) and posterior wall thickness (LVPWd) had not significant relationship with the duration of dialysis $(P>0.05)$.

\section{Discussion}

Cardiovascular diseases account for 40\%-50\% of mortality rate among hemodialysis patients, which is approximately 3 to 10 times more than that among healthy counterparts of the same age $(8,9)$.

In this study, we investigated the prevalence of echocardiographic findings in hemodialysis patients including calcification of cardiac valves, valvular disease, left ventricular systolic and diastolic dysfunction, and left ventricular hypertrophy in hemodialysis patients admitted to our hospital in Shahrekord. We also studied the relationship between above mentioned parameters with serum calcium, phosphorus, and parathyroid hormone, and also with duration of hemodialysis.

In this study, aortic valve calcification, mitral valve calcification, and mitral annulus calcification were observed in $20 \%, 1 \%$, and $4 \%$ of hemodialysis patients, respectively. In the study conducted by Jalali et al, mitral valve calcification and aortic valve calcification were observed in $3.9 \%$ and $1.9 \%$ respectively in hemodialysis patients, which were significantly lower than the values observed in our study (3). In another study by AvilaDiaz et al, the prevalence of mitral valve calcification, aortic valve calcification and calcification of both valves in hemodialysis patients were $26.3 \% 57.8 \%$, and $15.8 \%$ respectively (10). The prevalence of aortic valve calcification in the study by Avila-Diaz et al was somewhat similar to our study, however, the prevalence of mitral valve calcification was significantly higher. This disparity, especially the difference in the prevalence of aortic valve calcification can be due to the disparities in the age of the studied patients. Moreover, in the present study, the calcification of the mitral valve and mitral annulus were described separately, while they are reported collectively in other studies.

In the present study, serum calcium and parathyroid hormone levels were not significantly associated with the calcification of the heart valves, but serum phosphorous levels had a significant positive relationship with the calcification of the heart valves. In addition, the duration of dialysis did not have a significant relationship with the heart valves calcification. According to some studies, the calcification of heart valves has a significant relationship with calcium, phosphorus, and parathormone levels while other studies have not reported such a relationship. In the study of Raggi et al in 2002, the severity of calcification of the heart valves had a relationship with the duration of dialysis and serum phosphorus and calcium levels (6). Moreover, Avila-Diaz et al concluded that serum parathyroid hormone level was a major risk factor for the calcification of heart valves and had a direct relationship with valve calcification (10). In the study of MousaviMovahed et al, no significant relationship between serum calcium and phosphorus levels with calcification of the heart valves was detected. However, the prevalence of hyperparathyroidism among hemodialysis patients was $77 \%$, which it had a significant relationship with calcification of the heart valves (11). These differences can be due to the therapeutic effects of medications administered to the dialysis patients in various study groups.

In our cross-sectional study, we multiplied calcium by phosphorus in hemodialysis patients and the result was $44.95 \mathrm{mg}^{2} / \mathrm{dL}^{2}$. According to the study of Block et al, for every 10 units of $\mathrm{Ca} \times \mathrm{PO} 4$ product increase, the mortality rate of hemodialysis patients increased by $7 \%$ (12). In a study by Mills et al, $\mathrm{Ca} \times \mathrm{PO} 4$ product levels had a significant 
positive relationship with the stenosis of the heart valves (13). In fact, increasing the level of $\mathrm{Ca} \times \mathrm{PO} 4$ product in plasma leads to calcium deposition in the heart valves and increases blood pressure, which in turn may increase the risk of narrowing and insufficiency of the heart valves (14). Therefore, it is recommended to maintain serum calcium-phosphorus levels of hemodialysis patients within the normal range of less than $42 \mathrm{mg}^{2} / \mathrm{dL}^{2}$ to 55 $\mathrm{mg}^{2} / \mathrm{dL}^{2}$, to prevent the development and progression of cardiovascular diseases.

Of 100 hemodialysis patients, $71 \%$ had mild hypertrophy, $13 \%$ had moderate hypertrophy, and $1 \%$ had severe left ventricular hypertrophy. In the study of Yildiz et al, left ventricular hypertrophy in $69 \%$ of hemodialysis patients was observed. The reported prevalence is slightly lower than the prevalence observed in our study (15). Concerning the relationship between serum calcium, phosphorus, and parathyroid hormone with left ventricular hypertrophy, we found, left ventricular hypertrophy had no significant relationship with serum calcium and parathyroid hormone, though a significant positive relationship between serum phosphorus and left ventricular hypertrophy was detected. The risk factors associated with the prevalence of left ventricular hypertrophy are investigated by several studies (16-18). Some factors such as the duration of dialysis, age of patients, proportion of dialysis per week, and medical care after dialysis may affect the incidence of these disorders (3). In addition, the significant progress made in echocardiographic devices can be a cause of discrepancy between the results of various studies.

In the present study, pulmonary artery systolic pressure in a range of less than $35 \mathrm{~mm} \mathrm{Hg}$ was observed in 59\% of hemodialysis patients and pulmonary artery systolic pressure in a range of more than $35 \mathrm{~mm} \mathrm{Hg}$ was observed in $41 \%$ of hemodialysis patients. In a study by Sedighi et $\mathrm{al}$, the prevalence of pulmonary hypertension in hemodialysis patients was $44 \%$, which is similar to the results of the present study (19).

In our study, $81 \%$ of hemodialysis patients were suffering from grade I, $4 \%$ from grade II, and $2 \%$ from grade III of left ventricular diastolic dysfunction. We also found, 26 persons (26\%) had left ventricular systolic dysfunction. Jalali et al detected the prevalence of left ventricular dysfunction was estimated to be $18.4 \%$, which is somewhat similar to our study (3). Concerning the relationship between serum calcium, phosphorus and parathyroid hormone levels and left ventricular systolic and diastolic dysfunction, we found serum calcium, phosphorus and parathyroid hormone levels had no significant relationship with left ventricular diastolic dysfunction. Serum calcium and parathyroid hormone levels had no significant positive relationship with left ventricular systolic dysfunction, but serum phosphorus level had a significant relationship with left ventricular systolic dysfunction. Duration of dialysis had no significant relationship with left ventricular systolic and diastolic dysfunction.

\section{Conclusion}

Hyperphosphatemia was a risk factor for the prevalence of left ventricular hypertrophy, left ventricular systolic dysfunction, and calcification of the heart valves.

\section{Limitations of the study}

This study was a single center investigation, with a limited proportion of hemodialysis patients. We suggest larger multi-centric studies on this aspect of hemodialysis patients.

\section{Authors' contribution}

SM, MF and PI contributed to the study design and gathered the patients and their data. AN conducted all echocardiography of patients. MB conducted the analysis of data. SM, PI, MRT and MF prepared the primary draft. $\mathrm{SM}$ and MB prepared final revision. All authors read and approved the paper.

\section{Conflicts of interest}

The authors declare that they do not have any conflicts of interest.

\section{Ethical considerations}

Ethical issues (including plagiarism, data fabrication, double publication) have been completely observed by the authors.

\section{Funding/Support}

This article is extracted from general practitioner (M.D) thesis of Parisa Irannejad (Thesis \#1219).

\section{References}

1. Voinescu A, Martin KJ. Calcium, Phosphate, PTH, Vitamin $\mathrm{D}$ and FGF-23 in Chronic Kidney Disease. In: KalantarZadeh JD, ed. Nutritional Management of Renal Disease. 3rd ed. Academic Press; 2013:263-83.

2. Li H, Wang S. Cardiovascular Disease in Hemodialysis Patients. InTech; 2013.

3. Jalali F, Rezaei N, Namdar Z. Heart complication in patients with chronic kidney disease and on dialysis. J Babol Univ Med Sci. 2002;5:44-9.

4. Foley RN, Parfrey PS, Harnett JD, Kent GM, Martin CJ, Murray DC, et al. Clinical and echocardiographic disease in patients starting end-stage renal disease therapy. Kidney Int. 1995;47:186-92.

5. Daugirdas JT, Blake PG, Ing TS. Handbook of Dialysis. 4th ed. Philadelphia: Lippincott Williams and Wilkins; 2007.

6. Raggi P, Boulay A, Chasan-Taber S, Amin N, Dillon M, Burke SK, et al. Cardiac calcification in adult hemodialysis patients. A link between end-stage renal disease and cardiovascular disease? J Am Coll Cardiol. 2002;39:695701.

7. Baradaran A, Kheiri S, Kianmehr MR, Mortazavi M, Nasri 
H. Association of secondary hyperparathyroidism with coronary artery disease in patients on regular hemodialysis. Appl Med Inform. 2011;29:11-8.

8. Sonician M, Parissis JT. Cardiovascular diseases and hemodialysis: novel strategies for diagnosis, prevention and treatment. Hellenic J Cardiol. 2003;44:206-217.

9. Braunwald E, Fauci A, Kasper D. Harrison's principles of internal Medicine. 15th ed. New York: McGraw-Hill; 2001.

10. Avila-Diaz M, Mora-Villalpando C, Prado-Uribe Mdel C, Orihuela-Rodriguez O, Villegas-Antelo E, Gomez-Noriega $\mathrm{AM}$, et al. De novo development of heart valve calcification in incident peritoneal dialysis patients. Arch Med Res. 2013;44:638-44. doi: 10.1016/j.arcmed.2013.10.015.

11. Mousavi Movahed SM, Tabaraie Y, Alipour Nodoushan $\mathrm{KH}$, Zakarianejad M. Relationship between calcium, phosphorous and parathoromone with calcification of heart valves in dialyzed patients in Qom, 2006-2007. Qom Uni Med Sci J. 2008;2:21-7.

12. Block GA, Hulbert-Shearon TE, Levin NW, Port FK. Association of serum phosphorus and calcium x phosphate product with mortality risk in chronic hemodialysis patients: a national study. Am J Kidney Dis. 1998;31:607-17.

13. Mills WR, Einstadter D, Finkelhor RS. Relation of calciumphosphorus product to the severity of aortic stenosis in patients with normal renal function. Am J Cardiol.
2004;94:1196-8. doi: 10.1016/j.amjcard.2004.07.095.

14. Kahnooj M, Masoomi M, Naderinasab A, Zaeem A, Sheikhvatan M. Relationship between Calcium-Phosphorus Product and Severity of Valvular Heart Insufficiency in Patients Undergoing Chronic Hemodialysis. J Tehran Heart Cent. 2010;5:78-82.

15. Yildiz A, Oflaz H, Pusuroglu H, Mercanoglu F, Genchallac $\mathrm{H}$, Akkaya $\mathrm{V}$, et al. Left ventricular hypertrophy and endothelial dysfunction in chronic hemodialysis patients. Am J Kidney Dis. 2003;41:616-23. doi: 10.1053/ ajkd.2003.50123.

16. Nasri H. Serum leptin concentration and left ventricular hypertrophy and function in maintenance hemodialysis patients. Acta Fac Med Naiss. 2006;23:3-7.

17. Ha SK, Park HS, Kim SJ, Park CH, Kim DS, Kim HS. Prevalence and patterns of left ventricular hypertrophy in patients with predialysis chronic renal failure. J Korean Med Sci. 1998;13:488-94. doi: 10.3346/jkms.1998.13.5.488.

18. Lopez-Gomez JM, Verde E, Perez-Garcia R. Blood pressure, left ventricular hypertrophy and long-term prognosis in hemodialysis patients. Kidney Int Suppl. 1998;68:S92-8.

19. Sedighi O, Golshani S, Sharifpoor A, Mahjoob F. The prevalence of pulmonary hypertension and the related factors in hemodialysis patients. J Mazand Univ Med Sci. 2011;21:48-53. 